\title{
Prosody and levodopa in Parkinson's disease
}

\author{
Prosódia e levodopa na doença de Parkinson \\ Luciana Lemos de Azevedo', César Augusto da Conceição Reis², Irene Soares de Souza², \\ Francisco Eduardo Costa Cardoso ${ }^{4}$
}

\begin{abstract}
Objective: Research is scarce regarding the use of prosodic parameters in the expression of attitudes in Parkinson's disease (PD). The purpose of this study was to evaluate the parameters used in prosodic expression of attitudes in individuals with idiopathic PD and the effect of levodopa on these parameters. Method: We studied the use of levodopa in 10 individuals with idiopathic PD during the "off" and "on" periods, and 10 individuals without neurological abnormalities. Results: PD patients showed lower frequency measurements and longer duration measurements. The levodopa caused reduction in the duration parameter. Conclusion: PD patients use prosody to express their attitudes in the same way as controls in both off and on periods. However, when attitudes are not taken into account, levodopa is effective in improving the duration parameter.
\end{abstract}

Keywords: Parkinson's disease, speech acoustics, levodopa, voice.

\section{RESUMO}

Objetivo: A literatura é omissa quando questionada sobre o emprego dos parâmetros prosódicos na expressão das atitudes em parkinsonianos. O objetivo do presente estudo foi avaliar os parâmetros prosódicos empregados na expressão de atitudes em indivíduos com doença de Parkinson (DP) idiopática e a interferência da levodopa sobre esses parâmetros. Método: Foram estudados 10 indivíduos com DP idiopática, em uso de levodopa, nos períodos off e on e 10 indivíduos sem alterações neurológicas. Resultados: A DP faz com que os parkinsonianos apresentem menores medidas de frequência e maiores medidas de duração. A levodopa provocou redução no parâmetro duração. Conclusão: A DP não faz com que o sujeito use sua prosódia para expressar as atitudes de forma diferente do grupo controle, em ambos os períodos, offe on. No entanto, quando não são levadas em consideração as atitudes, observamos que a levodopa foi eficiente em melhorar o parâmetro de duração.

Palavras-chave: doença de Parkinson, acústica da fala, levodopa, voz.

Parkinson's disease (PD) involves motor impairment characterized by muscle rigidity and bradykinesia ${ }^{1,2}$ reflecting changes in voice and speech characteristics, marked by weak vocal intensity, low frequency modulation and imprecise articulation, with a detrimental effect on verbal communication in $70-90 \%$ of individuals ${ }^{3}$. These changes often affect speech intelligibility and can lead to a misinterpretation of the intention of PD patients, contributing to social isolation and negatively affecting their quality of life.

The literature contains few studies that deal with prosodic aspects of speech of PD patients and research is scarce regarding the effect of the use of prosodic parameters in the expression of attitudes. One study ${ }^{5}$ found reduced variability of fundamental frequency $\left(\mathrm{F}_{0}\right)$ in linked speech of individuals with idiopathic PD (IPD). Levodopa is the most effective drug for treating $\mathrm{IPD}^{6,7}$. In theory, all PD patients are treated with levodopa, which is converted into dopamine ${ }^{8}$. In addition to improving the symptoms of PD, levodopa is also associated with a decrease in the mortality rate of this population?.

In terms of voice and speech parameters, studies have reported the effect of levodopa on increasing $\mathrm{F}_{0}{ }^{10}$, melodic variation ${ }^{10}$ and vocal intensity ${ }^{11}$ after its administration, in

\footnotetext{
Study carried out at the Universidade Federal de Minas Gerais (UFMG), Belo Horizonte MG, Brazil.

'Speech and hearing therapist, Postdoctoral Fellow in Education from UFMG, Master and PhD in Linguistics Studies from UFMG, Specialist in Voice from CFFa, Specialist in Human Communication Disorders from UNIFESP, Associate Professor IV of PUC Minas;

${ }^{2}$ Linguist, PhD in Experimental and Applied Functional Phonetics from Université Aix Marseille I, France, and Postdoctoral studies at the Centre National de La Recherche Scientifique, France. Associate Professor IV of UFMG and Coordinator of the Laboratory of Phonetics of UFMG;

${ }^{3}$ Speech and hearing therapist, Postgraduate student in speech and hearing therapy and expressiveness from Universidade Gama Filho;

${ }^{4}$ Neurologist, Member of the Brazilian Academy of Neurology. Full Professor of the Clinical Medicine Department of UFMG.

Correspondence: Luciana Lemos de Azevedo; Rua Alagoas 1314 / sala 1313; Funcionários; 30130-160 Belo Horizonte MG - Brasil; E-mail: azevedoll@gmail.com

Conflict of interest: There is no conflict of interest to declare.

Received 15 April 2013; Received in final form 30 May 2013; Accepted 06 June 2013.
} 
addition to an improvement in speech intelligibility, type of voice $^{12}$ and speech rate, which became faster after levodopa administration ${ }^{10}$. Some authors ${ }^{13}$ observed a positive influence of levodopa in controlling airflow during phonation, in spite of observing no significant increase in respiratory volume or vocal intensity. Other authors ${ }^{14}$ also found a statistically significant increase in the maximum duration of phonation, due to the administration of levodopa. Another study ${ }^{15}$ reported the efficacy of the drug in reducing the degree of vocal tremor in patients with IPD and the elimination of tremor in some cases. However, some studies ${ }^{16,17}$ found a modest effect of this drug on prosodic aspects of parkinsonian speech, as only a few prosodic variables had changed after its use.

The aim of this study was to evaluate the prosodic parameters used in expression of attitudes of certainty and doubt in individuals with IPD and the interference of levodopa in improving these parameters. It is noteworthy that we found no studies in the literature that evaluated this issue.

\section{METHOD}

This study was approved by the Ethics Committee in Research of the Universidade Federal de Minas Gerais. The individuals involved signed a consent form approving their participation in the research.

\section{DEVELOPMENT OF A CORPUS}

We selected 10 individuals with IPD who were currently using levodopa: five males, 59-88 years old (average 70.8 years) and five females, 59-75 years old (average 67.4 years). In addition, we selected a control group (CG) comprising 10 individuals without neurological abnormalities: five males, 61-75 years old (average 69.8 years) and five females, 60-73 years old (average 66.4 years).

All individuals were submitted to neurological assessment (to identify and rule out possible significant hearing loss because of its impact on vocal quality) and larynx evaluations (in order to observe possible organic pathologies). For the neurological assessments, in the IPD group we selected those who had had a diagnosis of IPD (according to the Brain Bank of the British Parkinson's Disease Society ${ }^{18}$ ) and who were at stage 2-3 on the Hoehn and Yahr scale ${ }^{19}$. In the CG group, selected individuals had normal neurological evaluations.

Individuals who met the above selection criteria underwent corpus recording in a sound-treated room, for subsequent acoustic analysis. Individuals were asked to pronounce three sentences - "I closed the window", "I won the pot" and "I bought cinnamon" - in four different ways: expressing attitudes of certainty (AC) and doubt (AD), and declarative (DM) and interrogative (IM) modalities. The use of these modalities enabled a comparative study between DM and AC modalities and between IM and $\mathrm{AD}$ modalities; in the first pairing we can observe a downward melodic pattern, while in the latter pairing we can observe an upward melodic pattern ${ }^{20,21}$.

With regard to the production of sentences, a context was added by using the induction method so that the vocal production could be as natural as possible. Spontaneous speech, although ideal, cannot be studied in a comparative way. Thus, individuals were asked to pronounce the sentences previously presented on cards, embedded in a specific context, speaking in the most natural way possible.

The corpus was recorded on a Sony Digital Audio Tape (DAT) player/recorder, model PCM-M1,l using a Leson Hd-74, cardioid (unidirectional) headset microphone laterally positioned $2^{\prime \prime}(5 \mathrm{~cm})$ from the mouth of the speaker.

The CG conducted their recording (of approx. 15 minutes) in a single session, while the IPD group underwent recording in two phases: initially, after abstention of the use of levodopa for a period of 12 hours ("off") and then (part of the same corpus) one hour after administration of the drug ("on"). Therefore, this group was divided into two: individuals with PD outside the effect of levodopa ("off") and individuals with PD under the effect of levodopa ("on").

The corpus recording of each IPD patient was carried out on the same day, meaning that the individual underwent the recording in the off state, then took the levodopa medication and, after an hour, recorded the corpus in the on state. The recordings were always done in the mornings.

\section{PARAMETERS OF THE ANALYSIS}

Acoustic analysis was performed using a WinPitch ${ }^{\circledR}$ acoustic analysis program, version 1.8 (Philippe Martin, Toronto, Canada) and VoxMetria ${ }^{\circledR}$ version 2.0, which allowed the analysis of acoustic/prosodic parameters of $\mathrm{F}_{0}$, intensity and duration.

The $\mathrm{F}_{0}$ parameters analyzed were: higher value of $\mathrm{F}_{0}$ of the nuclear tonic syllable (NT), lower value of $\mathrm{F}_{0}$ of NT; amplitude of NT melodic variation, higher value of $\mathrm{F}_{0}$ of the unstressed pretonic syllable (immediately preceding nuclear tonic syllable) (APT); lower value of $\mathrm{F}_{0}$ of APT; amplitude of APT melodic variation; higher value of $\mathrm{F}_{0}$ of the utterance; lower value of $\mathrm{F}_{0}$ of the utterance; utterance composition; rate of change of NT melodic variation; rate of change of APT melodic variation; initial $\mathrm{F}_{0}$ of the utterance (taken in the middle of the vowel [e] of the word "I"); $\mathrm{F}_{0}$ of the APT (taken in the middle of the vowel [a]; the APT); $\mathrm{F}_{0}$ of the NT (taken in the middle of the vowel [E], the NT); and final $\mathrm{F}_{0}$ of the utterance (taken in the middle of the vowel [a] of the last word). Regarding the duration parameter we analyzed: NT length; APT length; total length of the utterance; start time of the APT; and start time of the NT. The intensity analysis 
involved the following parameters: maximum intensity of the utterance; minimum intensity of the utterance; intensity variation during the emission of the utterance; and utterance intensity average. The intensity measurements and the composition measurements ( $\mathrm{F}_{0}$ variability) were recorded using a VoxMetria ${ }^{\circledR}$ program and the other measurements were recorded using a WinPitch ${ }^{\circledR}$ program.

The analysis of the variables was subdivided into three groups:

(1) CG off $\nu s$ PD off: to verify any changes that occurred in the use of prosodic parameters due to $\mathrm{PD}$;

(2) CG on vs PD on: to examine whether the administration of levodopa minimizes, or even eliminates, the damage caused by the PD in the expression of attitudes through prosody;

(3) PD off vs PD on: to verify whether the administration of levodopa influences the use of prosodic parameters in the expression of attitudes in the parkinsonian patients.

The statistical analysis was performed using Minitab software (Minitab, PA, USA). We performed a statistical F test, using a significance level of $5 \%$, in order to determine possible differences between the groups and between the modalities and attitudes.

\section{RESULTS}

For all variables in the study, we first checked whether there was a statistically significant difference between males and females - as observed in the second column of Tables
1-3. If a significant difference existed, the variable was analyzed separately by gender, as can be seen in the last column of the tables, where the values for males and females were presented separately.

When comparing the groups CG off vs PD off, CG on vs PD on, and PD off $v s$ PD on, there was no statistically significant difference between the attitudes and modalities (DM x AC and IM $x \mathrm{AD}$ ), as observed in the first column of Tables 1-3. Therefore, all utterances for all three groups were analyzed together, not taking into account attitudes, as initially proposed.

In the CG off vs PD off group, there was a statistically significant difference between males and females regarding the melodic variation extent of NT and APT, and the rate of change of NT melodic variation, utterance length and average of utterance intensity (Table 1).

The variables of the $\mathrm{F}_{0}$ parameter that showed a statistically significant difference between CG off and PD off were: NT melodic variation extent, APT melodic variation extent in females, composition of utterance, and rate of change of the melodic variation of NT and APT. All these variables were higher in the CG.

Regarding the duration parameter, there was a statistically significant difference regarding the duration of NT and ATP, with a longer utterance length in males. For all these variables, the duration was shorter in the CG. For intensity measurements, only the average of utterance intensity in males was statistically significant different between the groups, being lower in the CG.

Table 1. Significance values $(p)$ when comparing attitudes \& modalities and males \& females, and their average and respective standard deviation and significance value $(p)$ in the comparison of data between CG off and PD off.

\begin{tabular}{|c|c|c|c|c|c|}
\hline \multirow[b]{2}{*}{ Variables } & \multicolumn{2}{|c|}{ p-value } & \multicolumn{2}{|c|}{ Average and standard deviation } & \multirow[b]{2}{*}{$p$-value } \\
\hline & $\begin{array}{c}\text { Attitudes \& } \\
\text { modalities }\end{array}$ & $\begin{array}{c}\text { Males }(m) \& \\
\text { females }(f)\end{array}$ & CG & PD off & \\
\hline \multirow[t]{2}{*}{ Amplitude of NT melodic variation (Hz) } & 0.75 & $0.00^{*}$ & $80.32 \pm 59.18$ & $30.40 \pm 27.83$ & $0.00^{*}(\mathrm{f})$ \\
\hline & & & $40.20 \pm 29.64$ & $17.11 \pm 12.30$ & $0.00^{*}(\mathrm{~m})$ \\
\hline \multirow[t]{2}{*}{ Amplitude of APT melodic variation $(\mathrm{Hz})$} & 0.11 & $0.05^{*}$ & $22.65 \pm 27.56$ & $13.43 \pm 7.90$ & $0.02^{*}(f)$ \\
\hline & & & $14.29 \pm 16.85$ & $11.70 \pm 9.50$ & $0.65(\mathrm{~m})$ \\
\hline Utterance composition $(\mathrm{Hz})$ & 0.41 & 0.74 & $139.86 \pm 62.82$ & $90.76 \pm 59.96$ & $0.00^{\star}$ \\
\hline Displacement presence of the NT (\%) & 0.30 & 0.10 & $19.17 \pm 39.53$ & $25.86 \pm 43.98$ & 0.19 \\
\hline \multirow[t]{2}{*}{ Rate of change of NT melodic variation ( $\mathrm{Hz} / \mathrm{ms})$} & 0.91 & $0.04^{*}$ & $0.46 \pm 0.33$ & $0.16 \pm 0.14$ & $0.00^{*}(f)$ \\
\hline & & & $0.29 \pm 0.21$ & $0.10 \pm 0.09$ & $0.00^{*}(\mathrm{~m})$ \\
\hline Rate of change of APT melodic variation ( $\mathrm{Hz} / \mathrm{ms})$ & 0.07 & 0.13 & $0.22 \pm 0.25$ & $0.12 \pm 0.10$ & $0.00^{*}$ \\
\hline NT duration (ms) & 0.76 & 0.27 & $150.46 \pm 37.60$ & $190.50 \pm 77.55$ & $0.00^{\star}$ \\
\hline APT duration (ms) & 0.81 & 0.22 & $85,72 \pm 22,04$ & $119.04 \pm 59.59$ & $0.00^{*}$ \\
\hline \multirow[t]{2}{*}{ Utterance duration (ms) } & 0.71 & $0.00^{*}$ & $1,308.90 \pm 209.20$ & $1,327.40 \pm 401.20$ & $0.99(f)$ \\
\hline & & & $1,140.20 \pm 272.20$ & $1,561.90 \pm 634.90$ & $0.00^{*}(\mathrm{~m})$ \\
\hline Intensity variation during the utterance (dB) & 0.55 & 0.55 & $41.66 \pm 5.56$ & $40.42 \pm 5.20$ & 0.07 \\
\hline \multirow[t]{2}{*}{ Utterance intensity average $(\mathrm{dB})$} & 0.93 & $0.00^{*}$ & $83.24 \pm 7.05$ & $82.87 \pm 7.75$ & $0.98(f)$ \\
\hline & & & $81.57 \pm 5.66$ & $86.19 \pm 5.14$ & $0.00^{*}(\mathrm{~m})$ \\
\hline Prolonged vowel intensity average [a] (dB) & - & 0.11 & $86.84 \pm 8.40$ & $81.95 \pm 8.86$ & 0.99 \\
\hline
\end{tabular}

APT: unstressed pretonic syllabe (immediately preceding nuclear tonic syllable); CG: control group; PD: Parkinson's disease; NT: nuclear tonic syllable. 
Table 2. Significance values $(p)$ when comparing attitudes \& modalities and females \& males, and their average and respective standard deviation and significance value $(p)$ in the comparison of data between CG on and PD on.

APT: unstressed pretonic syllabe (immediately preceding nuclear tonic syllable); CG: control group; PD: Parkinson's disease; NT: nuclear tonic syllable.

Table 3. Significance values $(p)$ when comparing attitudes \& modalities and males \& females, and their average and respective standard deviation and significance value $(p)$ in the comparison of data between PD off and PD on.

\begin{tabular}{|c|c|c|c|c|c|}
\hline \multirow[b]{2}{*}{ Variables } & \multicolumn{2}{|c|}{ p-value } & \multicolumn{2}{|c|}{ Average and standard deviation } & \multirow[b]{2}{*}{ p-value } \\
\hline & $\begin{array}{c}\text { Attitudes \& } \\
\text { modalities }\end{array}$ & $\begin{array}{c}\text { Males }(m) \& \\
\text { females ( } f \text { ) }\end{array}$ & PD off & PD on & \\
\hline Amplitude of NT melodic variation $(\mathrm{Hz})$ & 0.85 & 0.66 & $23.98 \pm 22.68$ & $22.20 \pm 19.61$ & 0.44 \\
\hline Amplitude of APT melodic variation $(\mathrm{Hz})$ & 0.90 & 0.39 & $12.66 \pm 8.64$ & $11.62 \pm 11.62$ & 0.43 \\
\hline Utterance composition $(\mathrm{Hz})$ & 0.99 & 0.81 & $90.76 \pm 59.96$ & $81.88 \pm 48.50$ & 0.29 \\
\hline Displacement presence of the NT (\%) & 0.98 & 0.95 & $25.86 \pm 43.98$ & $24.17 \pm 42.99$ & 0.77 \\
\hline Rate of change of NT melodic variation ( $\mathrm{Hz} / \mathrm{ms})$ & 0.88 & 0.29 & $0.13 \pm 0.12$ & $0.14 \pm 0.10$ & 0.52 \\
\hline Rate of change of APT melodic variation ( $\mathrm{Hz} / \mathrm{ms})$ & 0.86 & 0.59 & $0.12 \pm 0.10$ & $0.13 \pm 0.09$ & 0.48 \\
\hline Duration of the NT (ms) & 0.96 & 0.17 & $190.50 \pm 77.55$ & $150.40 \pm 44.00$ & $0.00^{*}$ \\
\hline \multirow[t]{2}{*}{ Duration of the APT (ms) } & 0.86 & $0.05^{*}$ & $110.84 \pm 35.99$ & $96.82 \pm 18.92$ & $0.31(f)$ \\
\hline & & & $128.40 \pm 77.60$ & $91.38 \pm 19.27$ & $0.00^{*}(\mathrm{~m})$ \\
\hline \multirow[t]{2}{*}{ Duration of the utterance (ms) } & 0.30 & $0.03^{*}$ & $1,327.40 \pm 401.20$ & $1,117.30 \pm 170.00$ & $0.02^{*}(f)$ \\
\hline & & & $1,561.90 \pm 634.90$ & $1,132.60 \pm 265.70$ & $0.00^{*}(\mathrm{~m})$ \\
\hline Intensity variation during the utterance (dB) & 0.83 & 0.21 & $40.42 \pm 5.20$ & $39.42 \pm 5.01$ & 0.13 \\
\hline Utterance intensity average $(\mathrm{dB})$ & 0.77 & 0.30 & $84.53 \pm 6.75$ & $85.63 \pm 7.15$ & 0.18 \\
\hline Prolonged vowel intensity average [a] (dB) & - & 0.97 & $81.95 \pm 8.86$ & $84.31 \pm 8.21$ & 0.45 \\
\hline
\end{tabular}

APT: unstressed pretonic syllabe (immediately preceding nuclear tonic syllable); CG: control group; PD: Parkinson's disease; NT: nuclear tonic syllable.

Tables 1-3 illustrate the significance values obtained after analyzing the variance (ANOVA), comparing: attitudes and modalities, males and females in each group, average values, and respective standard deviation and significance values.

In the CG on vs PD on group, statistically significant results were found regarding the $\mathrm{F}_{0}$ in terms of: the extent of NT melodic variation, the extent of APT melodic variation in females, composition of the utterance, and rate of change in NT melodic variation in both sexes, and in APT in females. All these variables were higher in the CG. Regarding the duration parameter, there was a statistically significant difference between groups for the duration of APT and utterance in females; both of these variables were lower in the CG. With regard to the intensity parameter, differences in intensity variation during utterance were statistically significant; intensity was higher in the CG and in the average 
intensity of utterance in males, and higher in $\mathrm{PD}$ on. The above data are shown in Table 2.

In the PD off $v$ s $\mathrm{PD}$ on group, the $\mathrm{F}_{0}$ and intensity parameters showed no statistically significant difference. Regarding the duration parameter, there was a statistically significant difference for NT duration, APT duration in males and utterance length. All variables were lower in PD on. The above data are shown in Table 3.

\section{DISCUSSION}

Comparing CG off with PD off, we observed that the variables related to the $\mathrm{F}_{0}$ parameter that were statistically different between the groups showed lower values in PD off. These findings corroborate with other studies ${ }^{10,17,22}$ that found lower amplitude of NT melodic variation in individuals with PD, giving speech a monotonous quality. The same studies show a lower rate of change of NT melodic variation in PD off compared with CG regarding the emission of short declarative utterances. Probably, this finding is due to the fact that PD patients present with bradykinesia, so the slowing of the vocal tract muscle reflects a slowing of the melodic variation of the segments. Some studies ${ }^{5,23,24}$ also reported a higher vocal composition in controls compared with PD patients. These findings correlate with the monotonous speech of PD patients found in this study. Durations were significantly higher for individuals with PD. This can also be explained by bradykinesia and difficulty in controlling air flow ${ }^{22,25,26}$.

Comparing CG off with PD off, we found lower average intensity of utterance in males. However, the literature ${ }^{23,27} \mathrm{in}$ dicates reduced vocal intensity in PD patients. One study ${ }^{10}$ reported that, in males, the intensity variation during the emission of short declarative utterances was lower for the $\mathrm{PD}$ off group. It is believed that these discrepancies are due to methodological issues, because the corpus does not represent spontaneous speech, but induced speech, leading to an artificial speech situation where speakers seek to improve their speech unconsciously, interfering with some results.

Comparing CG on and PD on, the variables of the $\mathrm{F}_{0}$ parameter were higher in CG. These findings negate the hypothesis that the use of levodopa would cause PD patients to obtain similar values to controls. However, they concur with one study ${ }^{10}$ that also verified the inefficiency of levodopa in improving the $\mathrm{PD} \mathrm{F}_{0}$ variables. This reinforces the concept that levodopa seems to be relevant only in improving duration, as it acts on bradykinesia ${ }^{10,16}$. However, some authors ${ }^{28}$ found higher $\mathrm{F}_{0}$ measurements in PD patients after administration of levodopa compared with controls.

Regarding utterance duration, the result differed from that expected in females, with longer duration of utterance in PD patients compared with controls. However, another study ${ }^{11}$ indicated that levodopa may cause an exacerbated increase in speech rate, possibly compromising speech intelligibility. In males, duration of both NT and utterance showed no statistically significant difference between PD on and CG, clarifying that the similarity of the NT duration in PD and CG was due to the use of levodopa. However, we observed a longer APT duration in $\mathrm{PD}$ on, demonstrating that, contrary to expectations, even after the administration of levodopa, PD patients maintained a longer APT duration, favoring a slower pattern emission.

The average of utterance intensity was significantly lower in CG males compared with PD on males, contradicting the hypothesis that levodopa would cause intensity increase in PD patients, though keeping it below the intensity found in the CG. The variation in intensity during the emission of the utterances, as expected, was higher in controls, negating the hypothesis that levodopa would lead to equalization in intensity levels between the groups, supporting the literature ${ }^{28}$.

Comparing PD off and PD on, only duration measurements presented a statistically significant difference, showing shorter duration in PD on, in agreement with the findings of other studies ${ }^{16,17}$. It is believed that this is because levodopa therapy attenuates bradykinesia, reducing the duration of speech segments during its period of action. However, another study ${ }^{17}$ indicated that $\mathrm{F}_{0}$ measurements were also significantly higher after levodopa administration.

Concerning intensity, an analysis ${ }^{13}$ of the effect of levodopa therapy on breathing and phonation in PD patients showed no significant increase in vocal intensity as a function of levodopa, but another investigation ${ }^{11}$ found that the vocal intensity of PD individuals tends to increase after levodopa therapy.

Motor deficits in PD may potentially improve through medication and surgery, but voice and speech are only partially responsive to drug therapy ${ }^{29,30}$.

The fact that this research has not shown any statistically significant difference between DM and AC, and between IM and $\mathrm{AD}$, confirms that the manner in which a $\mathrm{PD}$ patient uses prosody to express his/her attitudes does not differ from the way in which a control uses prosody, even after administration of levodopa.

\section{CONCLUSION}

By analyzing the prosodic parameters used in expression of attitudes of certainty and doubt in the IPD patients evaluated in this study, and the effect of levodopa on improving these parameters, we observed that the PD patients use prosody to express their attitudes in the same way as the control group, with respect to the prosodic parameters. However, we cannot rule out that this finding may have been influenced by the methodology used, more specifically by the analysis of an induced speech form that was not spontaneous speech. On 
the other hand, individuals with IPD showed lower $\mathrm{F}_{0}$ measurements and higher duration measurements, due to the administration of levodopa, which led to a reduction in the length of the utterances. This demonstrates the role of the drug in improving acoustic duration. However, even after the administration of levodopa, the $\mathrm{F}_{0}$ measurements continued to be lower in the control group, indicating that this drug does not positively influence this prosodic parameter. The intensity of the prosodic parameter, in turn, was found to be not relevant to this study of prosodic events in PD patients.

\section{References}

1. Obeso JA, Rodriguez-Oroz MC, Marin C, et al. Missing pieces in the Parkinson's disease puzzle. Nat Med 2010;1:653-661.

2. Peter A, Lewitt MD. Levodopa for the Treatment of Parkinson's Disease. New England J Med 2008;1:2468-2476.

3. Lima SSP, Quagliato EMAB, Cagliari LC, Souza EAP. Linguagem e isolamento social no mal de Parkinson. Rev Soc Bras Fonoaudiologia, Campinas 1997;1:5-13

4. Zarzur AP, Duarte IS, Gonçalves GNH, et al. Eletromiografia laríngea e análise vocal em pacientes com mal de Parkinson: estudo comparativo. Braz J Otorhinolaryngol 2010;1:40-43.

5. Knopp DB, Behlau M. Variabilidade da frequência fundamental na fala encadeada em indivíduos parkinsonianos. In: Behlau M, Gasparini G (eds). A voz do especialista. Rio de Janeiro: Revinter 2006;3:219-230.

6. Stocchi F, Rascol O, Kieburtz K, et al. Initiating levodopa/carbidopa therapy with and without entacapone in early Parkinson disease: The STRIDE-PD study. Ann Neurol 2010;1:18-27.

7. Peter A, Lewitt MD. Levodopa for the treatment of Parkinson's disease. New Engl J Med 2008;1:2468-2476.

8. Katzenschlager R, Lees AJ. Treatment of Parkinson's disease: levodopa as the first choice. J Neurol 2002;249:19-24.

9. Koller WC. Levodopa in the treatment of Parkinson's disease. Neurology 2000;55:2-7.

10. Azevedo LL. Aspectos prosódicos da fala do parkinsoniano. Dissertação (Mestrado em Linguística) - Faculdade de Letras da Universidade Federal de Minas Gerais. 2001:151p.

11. Jiang J, Lin E, Wang J, Hanson DG. Glottographic measures before and after levodopa treatment in Parkinson's disease. Laryngoscope 1999;109:1287-1294

12. Mourão LF. Estudo da comunicação oral em pacientes com doença de Parkinson em fase: "off" e "on", com o tratamento pela levodopa. Dissertação (Mestrado em Neurociências) - Universidade Federal de São Paulo. 1997; 74 pp.

13. Guedes LU,Azevedo LL, Cardoso F, Parreira VF, Reis C. Efeito da levodopa sobre a respiração e fonação dos indivíduos com doença de Parkinson idiopática. Rev Soc Bras Fonoaudiol 2005;suplemento especial.

14. Azevedo LL, Guedes LU, Cardoso F, Reis C, Parreira VF. Correlação da influência da levodopa sobre os aspectos motores, respiratórios e fonatórios dos indivíduos com doença de Parkinson. Rev Soc Bras Fonoaudiol 2005; suplemento especial.

15. Azevedo LL, Vieira RM, Cardoso F, Reis C. Efeito da levodopa no tremor vocal de pacientes parkinsonianos. Rev Soc Bras Fonoaudiol 2005; suplemento especial.
16. Azevedo LL, Cardoso F, Reis C. Análise acústica da prosódia em mulheres com doença de Parkinson - efeito da levodopa. Arq Neuropsiquiatr 2003;61:995-998.

17. Azevedo LL, Cardoso F, Reis C. Análise acústica da prosódia em mulheres com doença de Parkinson - comparação com controles normais. Arq Neuropsiquiatr 2003;61:999-1003.

18. Hughes AJ, Daniel SE, Kilford L, Lees AJ. Accuracy of clinical diagnosis of idiopathic Parkinson's disease: a clinico-pathological study of 100 cases. J Neurol Neurosurg Psychiatry 1992;55:181-184.

19. Hoehn MM, Yahr MD. Parkinsonism: onset, progression and mortality. Neurology 1967;17:427-442

20. Pike KL. The Intonation of American English. Ann Arbor: The Michigan University Press. 1945;1:1-106.

21. Moraes JA. Intonation in Brazilian Portuguese. In: Hist D, Di Cristo A (eds). Intonation Systems. London: Cambridge University Press 1998;1:179-194.

22. Fracassi AS, Gatto AR, Weber S, et al. Adaptação para a língua portuguesa e aplicação de protocolo de avaliação das disartrias de origem central em pacientes com doença de Parkinson. Rev CEFAC 2011;13:1056-1065.

23. Gamboa J, Jiménez FJJ, Nieto A, et al. Acoustic voice analysis in patients with Parkinson's disease treated with dopaminergic drugs. J Voice 1997;11:314-320.

24. Soares A, Brasolotto AG, Lamônica DAC, Saes SO, Parp P. Avaliação da voz de indivíduos com a doença de Parkinson. In: Anais do IX Congresso Brasileiro de Fonoaudiologia. Guarapari. 2001;617 pp.

25. Pereira JS, Cardoso SR. Distúrbio respiratório na doença de Parkinson. Fisioterapia Brasil 2000;2:23-26.

26. Cardoso SRX, Pereira JS. Análise da função respiratória na doença de Parkinson. Arq Neuropsiquiatr 2002;60:91-95.

27. Le Huche F, Allali A. Fonação e síndrome sistêmica. In: Le Huche F, Allali A (eds). A voz: patologia vocal de origem orgânica. Porto Alegre: Artmed 2005;3:102-144.

28. Goberman AM, Coelho C, Robb M. Phonatory characteristics of parkinsonian speech before and after morning medication: the ON and OFF states. J Commun Disord 2002;35:217-239.

29. Goberman AM. Correlation between acoustic speech characteristics and non-speech motor performance in Parkinson disease. Med Sci Monit 2005;11:109-116.

30. Sapir S, Ramig L, Fox C. Speech and swallowing disorders in Parkinson disease. Curr Opin Otolaryngol Head Neck Surg 2008;1:205-210. 